\title{
Phytochemicals Analysis, Antioxidant Capacities and Antimicrobial Properties of Ethyl Acetate Extract of Stem Bark of the Garlic Tree Scorodocarpus borneensis
} Becc.

\author{
Sudrajat Sudrajat, Dwi Susanto and Sudiastuti Sudiastuti \\ Department of Biology, Faculty of Mathematics and Natural Sciences, Mulawarman University, Jalan Barong Tongkok No. 4, \\ Samarinda 75123, East Kalimantan, Indonesia
}

\begin{abstract}
The objective of this study was to examine the phytochemical components, antioxidant activity and antibacterial property of ethyl acetate extract of the stem bark of garlic tree (Scorodocarpus borneensis). The dried stem bark of S. borneensis were collected and homogenized after drying at room temperature $\left(32{ }^{\circ} \mathrm{C}\right)$ for $30 \mathrm{~d}$. The stem barks were extracted by macerated method using $95 \%$ ethanol and then fractionated with ethyl acetate. The dried ethyl acetate extract was subjected to phytochemical screening to determine the presence of bioactive components using gas chromatography-mass spectrometry (GC-MS). Antioxidant activity of the extract in vitro was examined by 2,2-diphenyl-1-picryl-hydrazyl (DPPH) radical scavenging assay. The antibacterial activity against gram-positive bacteria Staphylococcus aureus and gram-negative bacteria Escherichia coli was performed by disc diffusion assay. GCMS results revealed the presence of 14 different phytocompounds, viz, tetratriacontyl trifluoroacetate (41.61\%), 2-pentanone (13.65\%), oxacyclotetradecane-2,11-done (7.87\%), cinnamic acid (7.53\%), 10-octadecanoic acid (6.50\%), 1,2-benzeno dicarboxylix acid (4.99\%), octadecanoic acid (4.51\%), hexadecanoic acid (4.16\%), beta tumerone (3.01\%), 9-octadecenoic acid $(1.70 \%)$, tricosanol (1.38\%), hexadecano-phenone (1.36\%), 1-nonadecanol (0.93\%) and n-nonadecanol (0.82\%). In vitro antioxidant activity $\left(\mathrm{IC}_{50}\right)$ was found at $55.524 \mathrm{ppm}$ as high powerful. The results of agar diffusion method showed that the ethyl acetate extracts had an antibacterial activity of $6.687 \pm 0.800 \mathrm{~mm}$ againts $S$. aureus at $10 \%(\mathrm{w} / \mathrm{v})$ and $7.500 \pm 0.735 \mathrm{~mm}$ against E. coli at $10 \%(\mathrm{w} / \mathrm{v})$ as moderate category. These findings suggest that $S$. borneensis stem bark is a valuable sources of bioactive compounds with promising as antioxidant and antibacterial sources.
\end{abstract}

Key words: Stem bark of Scorodocarpus borneensis, phytochemicals, antioxidant potential, antimicrobial properties.

\section{Introduction}

The use of plant compounds for pharmaceutical purposes has gradually increased in the world. Plants are very good sources of medicinal compounds that have continued to play a dominant role in the maintenance of human health since ancient times [1]. The effects of plant extracts on microorganism have been studied by a very large number of researchers in different parts of the world, and the use of a variety of plant extracts and phytochemicals of which both with

Corresponding author: Sudrajat Sudrajat, associate professor, research fields: forest biology, non-timber forest products and plant medicine. known antimicrobial properties can be of great significance in therapeutic treatments.

The garlic tree is a plant woody tree-shaped first-class, durable, and has a sharp smell like garlic. This garlic smell is present in the leaves, bark, wood, flowers and fruit or all parts of the plant. It is a woody plants living in a Dipterocarpaceae mixture forest area with a height of up to $700 \mathrm{~m}$ above sea level, and distributed at South Thailand, Sumatra, Lingga Island, Peninsular Malaysia and Borneo [2, 3]. This plant species is family Olacaceae members, who together about 30 genera and 250 species are distributed throughout tropical and subtropical regions. Olax 
scandens Roxb., Anacolosa griffithii Mast., Ochanostachys amentacea Mast., Scorodocarpus borneensis Becc., Strombosia philippinensis (Baill) Rolfe and Ximenia americana L. are medicinal plants in the Asia-Pacific region. Olacaceae is known as a producer of tannin, glycosida caynogenetic, polyacetylenic fatty acids, flavonoids and a series of polysulfide compounds [4]. The leaves include protein content $(3.7 \%)$, fat $(3.6 \%)$, carbohydrate $(11.6 \%)$, crude fiber (13.7\%), ash (0.9\%), P (46 mg), K (405 $\mathrm{mg}$ ), Mg (33 mg), Mn (20 ppm), Zn (10 ppm), vitamin $\mathrm{C}(3.5 \mathrm{mg})$, and only the old leaves can be used as a spice [5].

The fruit of the garlic tree contains sulfur compounds, such as 2,4,5-trithiahexane and 2,4,5,7-tertrathioctane 4,4-dioxide. These chemical compounds showed inhibitory effect on the metabolism of arachidonic acid and suppressed clumping of platelets in the blood cells of rabbits [2]. This fruit extract can be used to control some types of fungi in wood building, such as Candida albicans, Saccharomyces cerevisiae, Mucor racemosus and Aspegillus niger. The bioactive compounds are 2,4,5,7-tetrathiaoctane 4,4-dioxide; 5-thio-2,4,6 -trihiaheptane 2,2-dioxide; 0-ethyl-S-methyl-thiomethyl thiosulfite [6].

The leaves and fruit of garlic tree have very pungent odor and anti-fungal potential in a very strong category. There are two main sulfur-containing compounds, namely, bis-(methylthiomethyl)-disulphide and methylthiomethyl-(methylsulfonyl)-methyldi-sulphide; scopodin (new sesquiterpene); 8-isopropyl-5-methyl naphthoic acid and three types of new alkaloid tryptamine (scorodocarpin A, scorodocarpin B, scorodocarpin C) together with hemisynthetic sesquiterpene, cadalene- $\beta$-carboxylic acid isolated from the bark $[4,7]$. So the chemical constituent of stem bark and their potential as medicinal plant of $S$. borneensis, who known by locals as garlic tree, was selected as the study species. This paper aimed to analyze the phytochemical profile, antioxidant and antimicrobial activities of the stem bark of garlic tree
S. borneensis with ethyl acetate extract.

\section{Materials and Methods}

\subsection{Plant Materials}

Stem bark of garlic tree S. borneensis was collected from the Botanical Gardens of Mulawarman University, Samarinda, East Kalimantan, Indonesia $\left(0^{\circ} 30^{\prime} 00^{\prime \prime} \mathrm{S}, 117^{\circ} 09^{\prime} 00^{\prime \prime}\right.$ E). Plant species was identified by a taxonomist in Laboratory of Biodiversity, Faculty of Science, Mulawarman University. Plant samples collected from field was cut into pieces and dried at room temperature in the laboratory for two weeks. Then, stem bark was milled and sieved with a sieve sized of 40-60 mesh. The powdered bark was kept in a constant room until the moisture content of approximately $15 \%$.

\subsection{Extraction and Fractionation}

The dried powder of stem bark of S. borneensis (2.5 $\mathrm{kg}$ ) was macerated with $95 \%$ ethanol in a glass container with a ratio of $1: 1$ at room temperature. After maceration $9 \mathrm{~d}$, the extracts were filtered using Whatman No. 1 filter paper. The filtrate then was concentrated to dryness by a rotary evaporator and dried in a fume hood until dried crude paste formed. The yield extract was brownish $(20.50 \mathrm{~g}, 0.82 \%)$. The ethanol extract was fractionated with ethyl acetate and evaporated using vacuum rotary and then the antimicrobial property tested by agar diffusion method. The antioxidant activity was tested with 2,2-diphenyl-1-picryl-hydrazyl (DPPH) free radical method. Further, the content of bioactive compounds of extract was analyzed prior isolation using column chromatography.

The ethyl acetate extract of stem bark S.borneensis $(1 \mathrm{~g})$ was loaded on a silica gel column eluted with a mixture of chloroform:methanol:water $=7: 3: 1$. The absorbance of the fractions eluted from the column chromatography was measured at a resolution from 254-366 nm using UV-Visible spectrophotometer and 
the readings were recorded. The fractions that were eluted in column chromatography using chloroform and ethyl acetate (2:8) exhibiting activity was subjected to GC-MS equipped with a Shimadzu QP2010 GC/MS apparatus (Shimadzu Corp., Japan) to find out the active principle of the extracts.

In this research, essential oil was obtained as golden yellow with aroma typical garlic odor. Essential oil column chromatographic isolation results were analyzed by gas chromatography-mass spectrometry (GC/MS) Shimadzu QP2010S.

\subsection{GC-MS Analysis}

A shimadzu Qp-2010 GC-MS was used. The GC-MS was equipped with Ri-5MS column Rastex capillary ( $30 \mathrm{~m}, 0.25 \mathrm{~mm}$, ionization: EI $70 \mathrm{Ev}$ ), heated at a temperature of $80{ }^{\circ} \mathrm{C}$, pressure of $16.5 \mathrm{kPa}$, total flow of $20.0 \mathrm{~mL} / \mathrm{min}$, column flow of $0.50 \mathrm{~mL} / \mathrm{min}$, linear velocity $26.1 \mathrm{~cm} / \mathrm{s}$, purge flow $3.0 \mathrm{~mL} / \mathrm{min}$, injector and detector temperature was $310{ }^{\circ} \mathrm{C}$, using helium as the carrier gas, at a flow rate $3.0 \mathrm{~mL} / \mathrm{min}$. Interpretation on mass spectrum of GC-MS was done using the database of National Institute Standard and Technology (NIST) having more than 62,000 patterns. The mass spectrum of the unknown component was compared with the spectrum of the known components stored in the NIST08 and Wiley08 library. The name, molecular weight and structure of the components of the test materials were ascertained.

\subsection{Antibacterial Assay}

The antibacterial test was performed by agar disc diffusion method [8] using Muller Hinton agar No. 2 medium. The assay of microbial growth was determined by measuring the diameter of the zone of inhibition (mean \pm standard deviation). Inoculating of the bacterial using a sterile cotton swab was dipped into the adjusted suspension and used to streak all over the dried surface of a sterile Muller Hinton agar plate. This streaking process was repeated 2-3 times to ensure that the test organisms were evenly distributed. The inoculum was allowed to diffuse into the agar for about $10 \mathrm{~min}$. Four wells $(6 \mathrm{~mm})$ were aseptically made using sterile cork borer of equidistance to each other. The fixed volume $0.1 \mathrm{~mL}(100 \mu \mathrm{L})$ of the plant extract at different concentrations was carefully placed into each holes, while the 4th hole contained a broad spectrum antibiotic (Chloramphenicol) as control.

The plates were prepared in triplicates and then incubated at $37{ }^{\circ} \mathrm{C}$ for $18-24 \mathrm{~h}$. The zone of inhibition of each well was obtained by measuring the underside of the plate in two planes with a ruler calibrated in millimeter.

\subsection{Evaluation of Antioxidant Activity by DPPH Radical Scavenging Assay}

The antioxidant potential activity of the bark stem extract of S. borneensis was assessed according to the method described by Scherer and Godoy [9]. This method is based on the DPPH radical test. Briefly, the working reagent was prepared by dissolving $10 \mathrm{mg}$ of DPPH in $100 \mathrm{~mL}$ methanol. Graded concentration of extracts was $1,5,10,20,40,80$ and $100 \mu \mathrm{g} / \mathrm{mL}$. Tests were carried out with extracts and reference antioxidant vitamin $\mathrm{C}$ and vitamin $\mathrm{E}$ in concentrations ranging from $1 \mu \mathrm{g} / \mathrm{mL}$ to $100 \mu \mathrm{g} / \mathrm{mL}$.

The DPPH test is based on the ability of the extracts to donate a radical hydrogen to scavenge the stable DPPH radical. When this radical reacts with the antioxidant compound, it is reduced with the loss of the deep violet colour to light-yellow. The absorbance is measured at $517 \mathrm{~nm}$ on a visible light spectrophotometer. Free radical scavenging activity was measured by a decrease in absorbance at $517 \mathrm{~nm}$ of a solution of coloured DPPH in methanol brought about by the sample. $\mathrm{IC}_{50}$ was calculated from percentage of antioxidant activity.

The percent of DPPH radical scavenging activity is calculated as Eq. (1):

DPPH radical scavenging activity $(\%)=$

$$
\left[\left(A_{\text {blank }}-A_{\text {extract }}\right) / A_{\text {blank }}\right] \times 100
$$


where, $A_{\text {blank }}$ is the absorbance of blank sample (time $=30 \mathrm{~min}$ ) and $A_{\text {extract }}$ is the absorbance of the essential oil sample (time $=30 \mathrm{~min})$.

$\mathrm{IC}_{50}$ (concentration providing $50 \%$ inhibition) of extracts was determinate using regression curves in the linier range of concentrations. The antioxidant activity index (AAI) was calculated as Eq. (2):

$\mathrm{AAI}=$ the final concentration of $\mathrm{DPPH} / \mathrm{IC}_{50}$

According to the criteria of Sherer and Godoy [9], plants extracts show poor antioxidant activity when AAI $<0.5$, moderate antioxidant activity when between 0.5 and 1.0, strong antioxidant activity when between 1.0 and 2.0, and very strong when $\mathrm{AAI}>2.0$.

\subsection{Data Analysis}

Observation of the inhibitory activity of bacteria is done by measuring the diameter of inhibitory regions (DDH) formed around the wells.

\section{Results}

\subsection{Phytochemical Composition of the Extract}

The result of phytochemical analysis revealed that the ethyl acetate bark extracts of $S$. borneensis had contents of alkaloid, phenolic and triterpenoid. The gas chromatography profile of this extract was displayed in Fig. 1 and Table 1.

It was found that the ethyl acetate fraction of the stem bark of $S$. borneensis was a complex mixture (Table 1). The largest compounds in ethyl acetate extract were tetratriacontyl trifluoroacetate (41.61\%), 2-pentanone (13.65\%), oxacyclotetradecane-2,11-done (7.87\%), 3-phenyl-2-propenoate acid (cinnamic acid) (7.53\%), 10-octadecenoic acid methyl ester (6.5\%), 1,2-benzenodicarboxylic acid-dioctyl ester (phtalate acid) (4.99\%), hexadecanoic acid-methyl ester (4.16\%), 9-octadecenoic acid (ethyl oleate) (1.7\%) and hexadecano-phenone (1.36\%).

\subsection{Antibacterial Activities}

The result of the susceptibility profile of test organisms is shown in Table 2. Extract of ethyl acetate stem bark of $S$. borneensis was able to inhibit most of the bacterial test organisms with measurable zones of inhibitions. The standard (chloramphenicol) showed an average inhibition diameter of $15.78 \mathrm{~mm}$. The average inhibition zone is the highest at concentrations of $10 \%$

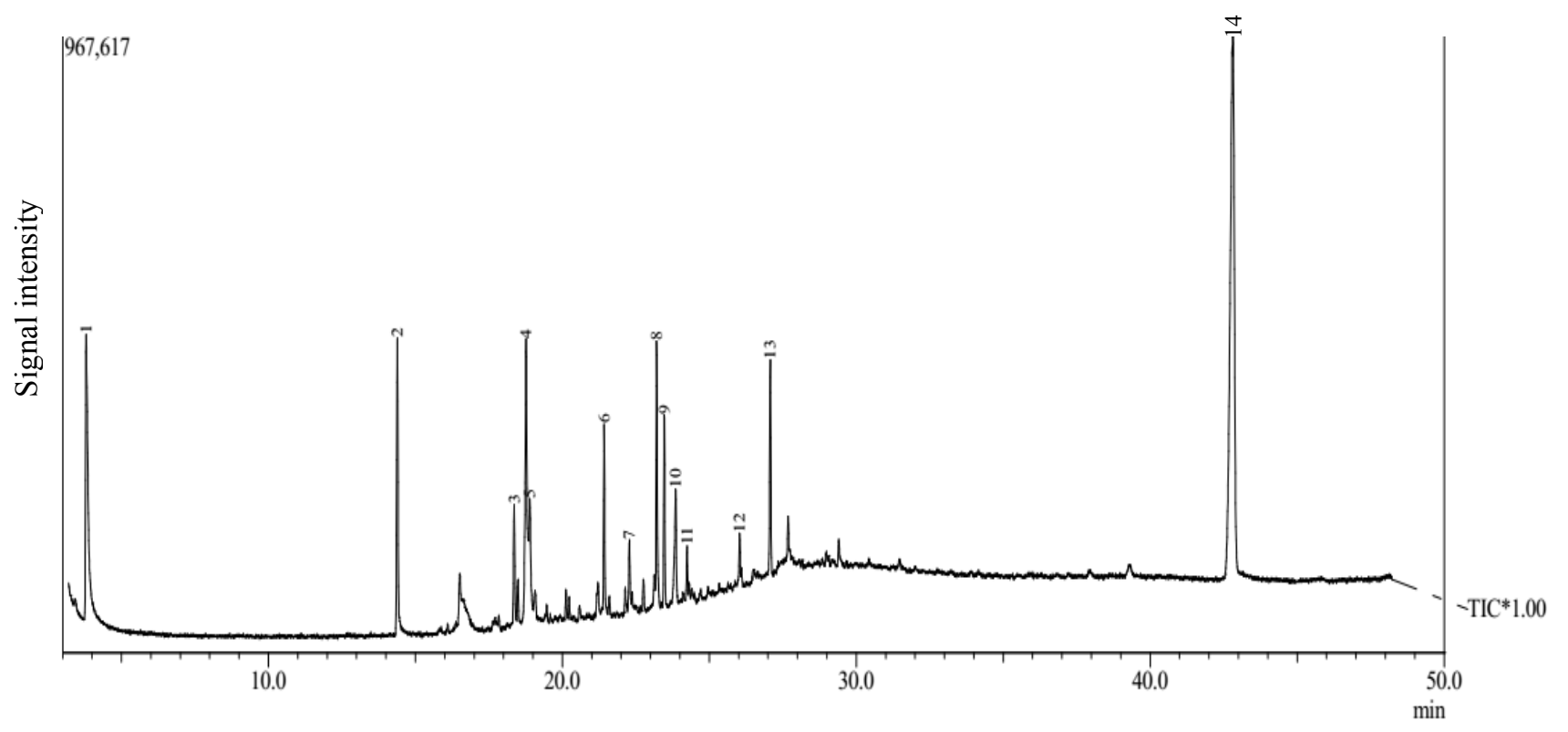

Retention time (min)

Fig. 1 Chromatogram of ethyl acetate fraction of the stem bark of garlic tree $S$. borneensis. TIC $=$ total ion chromatogram. The mean 967,617 is unit respond detector as signal intensity. 
Acetate Extract of Stem Bark of the Garlic Tree Scorodocarpus borneensis Becc.

Table 1 The identified constituents of the ethyl acetate extracts of stem bark of $S$. borneensis.

\begin{tabular}{llll}
\hline Peak & Retention time $(\mathrm{min})$ & Name of compound & Peak area (\%) \\
\hline 1 & 3.801 & 2-pentanone & 13.65 \\
2 & 14.387 & Cinnamic acid & 7.53 \\
3 & 18.361 & -turmerone & 3.01 \\
4 & 18.706 & Oxacyclotetradecane-2,11-done & 7.87 \\
5 & 18.891 & Hexadecano-phenone & 1.36 \\
6 & 21.260 & Hexadecanoic acid & 4.16 \\
7 & 22.281 & Tricosonal & 1.38 \\
8 & 23.211 & 10-octadecanoic acid & 6.50 \\
9 & 23.470 & Octadecanoic acid & 4.51 \\
10 & 23.855 & 9-octadecenoic acid & 1.70 \\
11 & 24.242 & 1-nonadecanol & 0.93 \\
12 & 26.028 & n-nonadecanol & 0.82 \\
13 & 27.074 & 1,2-benzenodi carboxylic acid & 4.99 \\
14 & 42.815 & Tetratriacontyl trifluoroacetate & 41.61 \\
\hline
\end{tabular}

Table 2 Antibacterial activities of the stem barks extract of garlic tree $S$. borneensis at different concentrations.

\begin{tabular}{llllll}
\hline \multirow{2}{*}{ Microorganisms } & \multicolumn{5}{c}{ Zone of inhibition $(\mathrm{mm})$} \\
\cline { 2 - 6 } & $2.5 \%(\mathrm{w} / \mathrm{v})$ & $5 \%(\mathrm{w} / \mathrm{v})$ & $7.5 \%(\mathrm{w} / \mathrm{v})$ & $10 \%(\mathrm{w} / \mathrm{v})$ & Chloramphenicol \\
\hline Staphylococcus aureus & $3.562 \pm 1.264$ & $6.437 \pm 3.255$ & $6.437 \pm 0.554$ & $6.687 \pm 0.800$ & $15.780 \pm 2.334$ \\
Escherichia coli & $4.437 \pm 0.850$ & $6.250 \pm 0.735$ & $7.437 \pm 0.625$ & $7.500 \pm 0.735$ & $15.780 \pm 2.334$ \\
\hline
\end{tabular}

Data represent mean \pm standard error of zonal inhibition of bacteria.

Table 3 Inhibition radicals scavenging by fraction of ethyl acetate extract of stem bark of garlic tree $S$. borneensis.

\begin{tabular}{llll}
\hline Substance & Concentration samples $(\mathrm{ppm})$ & Radical scavenging inhibition (\%) & $\mathrm{IC}_{50}(\mathrm{ppm})$ \\
\hline & 100 & 84 & 55.524 \\
Ethyl acetate extract of stem & 50 & 50 & \\
bark of garlic tree S.borneensis & 25 & 26 & 14.130 \\
& 12 & 15 & \\
\hline & 6 & 6 & \\
Ascorbic acid & 50 & 68 & 14.692 \\
(vitamin C) & 25 & 48 & \\
& 12 & 38 & \\
\hline & 6 & 80 & \\
Vitamin E & 50 & 61 & \\
$(\alpha$-tokoferol) & 25 & 48 & \\
& 12 & 41 & \\
\hline
\end{tabular}

against the bacteria $S$. aureus with an average of 6.687 $\mathrm{mm}$ zone of inhibition, while the highest inhibitory zone at a concentration of $10 \%$ against the bacteria $E$. coli with an average of $7.5 \mathrm{~mm}$ inhibition zone.

\subsection{Antioxidant Activities}

Plants with radical scavenging property and antioxidant capacity are useful for medicinal applications and as food additive. So, in the present study, the antioxidant capacity of $S$. borneensis was evaluated using DPPH radical scavenging method by comparing with the activity of the vitamin $\mathrm{C}$ and $\mathrm{E}$ as a known antioxidant. Results shown in Table 3 revealed that the antioxidant activities $\left(\mathrm{IC}_{50}\right)$ of ethyl 
acetate extract of stem bark S. borneensis were 55.524 ppm. Regarding the $\mathrm{IC}_{50}$ values calculated, the lower of $\mathrm{IC}_{50}$ also has higher antioxidant activity.

\section{Discussion}

Studies have been carried out to discover useful antibacterial of S. borneensis. This extract showed the inhibition of the growth of all bacteria with varying effects. The fraction of ethyl acetate extracts for antibacterial activity increases with the increase in concentration. The results of this test showed that the bark extract indicates the existence of compounds as antibacterial. S. borneensis bark stem extract showed better antibacterial properties against gram-negative bacteria $(E$. coli) than gram-positive bacteria ( $S$. aureus).

This result is slightly different from that reported by Kubota et al. [10,11], who obtained the result that the antibacterial properties of the fruit garlic tree has a broad spectrum against bacteria S. aureus, E. coli, B. subtilis and some fungi, such as C. albicans, $S$. cerevisiae, $M$. racemosus and A. niger. The bioactive compounds show that $S$. borneensis contained sulphuric compounds identified as methyl methylthiomethyl disulphide and bis-(methylthiomethyl) disulphide $\left(\mathrm{MSO}_{2}\right)$, which gave characteristic aroma similar to garlic.

Antibacterial activity of extracts allegedly is associated with the presence of the active compound, which can interfere with the metabolism of bacteria, so that bacteria growth is inhibited or death, and also because of the secondary metabolites of the compounds contained in the bark. Result from GC-MS analysis indicated that the ethyl acetate extract was dominated by tetra triacontyl trifluoro acetate (41.61\%), 2-pentanone (13.65\%), oxacyclotetradecane 2,11-done (7.87\%), 3-phenyl-2-propenoic acid (7.53\%), 10-octadecenoic acid methyl ester (6.50\%), 1,2-benzenodicarboxylic acid-dioctyl ester (4.99\%) and hexadecanoic acid (4.16\%). According to Brooks et al. [12], the inhibited growth of bacteria or bacterial death due to an antibacterial agent may be through inhibition of cell wall synthesis, cell membrane function, protein synthesis or nucleic acid synthesis.

Extract of S. borneensis which was tested for antibacterial activity was found to have a broad spectrum effect on growth of common pathogenic bacterial, S. aureus and E. coli. The result in this study showed that there was antibacterial activity tends to agree with similar work with same family Olacaceae, Ximenia americana, which exerted more broad spectrum inhibitory activity against the microorganism $[13,14]$. These results indicate that the bark extract of garlic tree (S. borneensis) can be an alternative new antibacterial for against cases of infectious diseases in the isolated area. Based on the test results of phytochemical analysis, the ethyl acetate extracts of garlic tree (S. borneensis) consisted of alkaloids, phenolic and triterpenoids. Thus, it should be explored further for pharmaceutical uses, as this is particularly important in combating the recent observation of the emergency of drug resistant bacteria at inlands area.

From Table 3, it can be seen the antioxidants from a fraction potential of the ethyl acetate extract of stem bark of Garlic tree $S$. borneensis, where $\mathrm{IC}_{50}$ value indicates antioxidant potential, but this potential was under vitamin $\mathrm{C}$ and vitamin $\mathrm{E}$. In terms of phytochemical test results, it appears that the ethyl acetate extract fraction of stem bark contains bioactive compound which have allegations of antioxidant potential. The results showed that the ethyl acetate extract of $S$. borneensis compounds contained phenolic derivatives including cinnamic acid, 2-pentanone and 1,2-benzenodicarboxylic acid, and fatty acid including palmitic acid, octadecanoic acid and hexadecanoic acid, which have been reported as an antioxidant $[15,16]$.

Antioxidants are the substances that have the ability to reduce or prevent the process of lipid oxidation. The higher levels of bioactive compounds in a food, the higher the antioxidant activity. In this study, 
antioxidant activity $\mathrm{IC}_{50}$ was used. According Sharma et al. [17], $\mathrm{IC}_{50}$ value is to express the concentration of antioxidant compounds that cause $50 \%$ of DPPH free radical loss of character. In this research, the extract ethyl acetate stem bark of garlic tree, S. borneensis had $\mathrm{IC}_{50}$ value of $55.524 \mathrm{ppm}$. Based on report by Molyneux [18], this value shows the strong antioxidant activity category. While, based on this of AAI according to Sherer and Godoy [9], the sample possesses poor antioxidative ability when the AAI < 0.5 , average between 0.5 and 1.0 , strong between 1.0 and 2.0 and very strong $>2.0$. In this work, the ethyl acetate of the bark $S$. borneensis AAI $=14.130 / 55.524$ $=0.254$, indicating poor antioxidative ability as an antioxidant.

\section{Conclusions}

Results from this study showed that the bark of $S$. borneensis possessed potential to be developed as natural antibacterial agents against pathogenic bacteria and antioxidants source. GC-MS analysis indicated that ethyl acetate fraction was dominated by fatty alcohol, phenol, triterpene, carboxylic acid, phtalate acid and fatty acid. This result supports the use of this plant in traditional medicine for treatment of different diseases. The antimicrobial bioassay tests of the ethanolic extract of $S$. borneensis bark showed not significant different activity against $S$. aureus and $E$. coli. The plant could be a veritable and cheaper substitute for conventional drugs, since the plant is easily obtainable and the extract can easily be made via simple processes of maceration or infusion. Thus, it should be explored further for pharmaceutical uses, as this is particularly important in combating the recent observation of the emergency of drug resistant bacteria and antioxidant.

\section{Acknowledgments}

The authors would like to thank Indonesian Directorate General of Higher Education (DIKTI) for providing the fund, and Mr. Jamransyah Jamransyah and Singkir Singkir for help and contributions during field work and in the laboratory.

\section{References}

[1] Moriita, R. M., Ogal, C., Oguge, N. O., and Okemo, P. O. 2011. "Methanol Extracts of Three Medicinal Plants from Samburu in Northern Kenya Show Significant Antimycobacterial, Antibacterial and Antifungal Properties.” Res. J. Med. Plants 5 (1): 54-64.

[2] Lim, H., Kubota, K., Kobayashi, A., Seki, T., and Ariga, T. 1999. "Inhibitory Effect of Sulfur Containing Compounds in Scorodocarpus borneensis Becc. on the Aggregation of Rabbit Platelet." Biosci. Biotechnol. Biochem. 63 (2): 298-301.

[3] Lesmy, T. 2007. "Olacaceae." In Tree Flora of Sabah and Sarawak, edited by Soepadmo, E., and Wong, K. M. Vol. 1. Malaysia: Forest Research Institute, 271-86.

[4] Wiart, C., Martin, M. T., Awang, K., Hue, N., Serani, L., Laprevote, O., Pais, M., and Rahman, M. 2001. "Sesquiterpenes and Alkaloids from Scorodocarpus borneensis." Phytochemistry 58 (4): 653-6.

[5] Hoe, V. B., and Siong, K. H. 1999. "The Nutritional Value of Indigenous Fruits and Vegetables in Sarawak." Asia Pasific J. Clin. Nutr. 8 (1): 24-31.

[6] Verma, R. K., Chaurasia, L., and Katiyar, S. 2008. "Potential Antifungal Plants for Controlling Building Fungi." Natural Product Radiance 7 (4): 374-87.

[7] Mawardi, R. 2003. "Chemical Diversity of Malaysia Flora: Potential Source of Rich Therapeutic Chemicals." Inaugural Lecture, Faculty of Science, Universiti Putra Malaysia Institutional Repository (UPMIR). Accessed June 9, 2009. http://psasir.upm.edu.my/1112/.

[8] Bauer, A. W., Kirby, W. M., Sherris, J. C., and Turck, M. 1966. "Antibiotic Susceptibility Testing by a Standardized Single Disk Method." Am. J. Clin. Pathol. 45 (4): 493-6.

[9] Sherer, R., and Godoy, H. T. 2009. "Antioxidant Activity Index (AAI) by 2,2-Diphenyl-1-Picrilhydrazyl Method." Food Chemistry 112: 654-8.

[10] Kubota, K., Matsumoto, M., Ueda, M., and Kobayashi, A. 1994. "New Antimicrobial Compound from Scorodocarpus borneensis Becc.." Biosci. Biotech. Biochem. 58 (2): 430-1.

[11] Kubota, K., Ohhira, M., and Kobayashi, A. 1994. "Identification and Antimicrobial Activity of the Volatile Flavor Constituents from Scorodocarpus borneensis Becc..” Biosci. Biotech. Biochem. 58 (4): 644-6.

[12] Brooks, G. F., Butel, J. S., and Morse, S. A. 2003. "Cell Structure." In Jawetz, Melnick \& Adelberg's Medical Microbiology, 22nd ed.. Lange USA: Medical Books/ 
McGraw-Hill, 7-37.

[13] Maikai, V. A., Maikan, B. V., and Kobo, P. I. 2009. "Antimicrobial Properties of Stem Bark Extracts of Ximenia ameicana." J. Agri. Sci. 1 (2): 30-4.

[14] Zeinab, M., Ali Ahmed, M., Saeed, E. M., and Khalid, H. S. 2016. "Antimicrobial Activity and Phytochemical Screening of Ximenia americana L. Bark and Leaves." American J. Res. Comm. 4 (1): 122-9.

[15] Mousa, N. K., Khudier, S. H., Mohammad, A. N., Sabbar, S. S., and Ahmed, I. A. 2013. "Antioxidant Activity of Cinnamic Acid against Trichlorfon in Mice." Iraqi J. Biotechnology 12 (2): 54-62.
[16] Sudha, T., Chidambarampillai, S., and Mohan, V. R. 2013. "GC-MS Analysis of Bioactive Components of Aerial Parts of Fluggea leucopyrus Willd. (Euphorbiaceae)." J. Appl. Pharmacol. Sci. 3 (5): 126-30.

[17] Sharma, G. N., Dubey, S. K., Sati, N., and Sanadya, J. 2011. "Phytochemical Screening and Estimation of Total Phenolic Content in Aegle marmelos Seeds." Inter. J. Pharm. and Clin. Res. 3 (2): 27-9.

[18] Molyneux, P. 2004. "The Use of the Stable Free Radical Diphenyl Picrylhydrazyl (DPPH) for Estimating Antioxidant Activity." Songklanakarin J. Sci. Technol. 26 (2): 211-9. 